\title{
Rapid and simple design approach of micro-strip Butler matrix beam-forming network for wireless system
}

\author{
Goh Chin Hock ${ }^{\mathrm{a})}$, Chandan Kumar Charabarty, \\ Tiong Sieh Kiong, and Oon Kheng Heong \\ Department of Electronic and Communication Engineering, \\ Universiti Tenaga Nasional (UNITEN), \\ Jalan IKRAM-UNITEN, 43000, Kajang, Selangor, Malaysia \\ a)chinhock@uniten.edu.my
}

Abstract: In this work, a rapid and simple approach is facilitating the design of Butler matrix beam-forming network (BMN). Generally, BMN structure is occupying huge area of printed circuit board and required large amount of mesh cells for better simulation accuracy. The proposed approach has reduced design steps and improves the simulation time. Although, designers can use better mainframe and graphics processing unit in order to improve the simulation time, the devices come with simulation cost. The entire BMN is divided into smaller and simple structure as the standard re-use electromagnetic model in order to study the parasitic elements and essential actual phase progression.

Keywords: Butler beam-forming network, phase shift, electromagnetic model

Classification: Microwave and millimeter wave devices, circuits, and systems

\section{References}

[1] J. Butler and R. Lowe, "Beam-forming Matrix Simplifies Design of Electrically Scanned Antennas," Electronic Design, vol. 12, pp. 170-174, 1961.

[2] CST Microwave Studio®, User Manual Version 2010, MICROWAVE STUDIOR, is trademark of CST GmbH.

[3] E. Hammerstad, "Computer-Aided Design of Microstrip Couplers with Accurate Discontinuity Models," Symp. Microwave Theory and Techniques, pp. 54-56, June 1981.

[4] K.-O. Sun, S.-J. Ho, C.-C. Yen, and D. Van der Weide, "A Compact Branch-line Coupler Using Discontinuous Microstrip Lines," IEEE Microw. Wireless Compon. Lett., vol. 15, no. 8, pp. 519-520, 2005.

[5] G. A. E. Vandenbosch and A. Vasylchenko, "A Practical Guide to 3D Electromagnetic Software Tools," InTech Publisher, 2011.

[6] K. C. Gupta, T. Itoh, and A. A. Oliner, "Microwave and RF EducationPast, Present, and Future," IEEE Trans. Microw. Theory Tech., vol. 50, no. 3, pp. 1006-1014, 2002. 


\section{Introduction}

Butler matrix beam-forming network (BMN) [1] is an essential component in the switched beam phased array antenna system. It is used to contribute a uniform distribution phase difference between consecutive outputs of the array antenna elements. The BMN performs a spatial fast Fourier transform (FFT) of the inputs. In general, a $4 x 4$ micro-strip BMN can be developed with three main microwave components which includes of four branch-line couplers, two crossover couplers and two phase shifters. In this work, circuit mapping and actual phase shift is study in order to understand the BMN architecture and attempt to reduce the design step as well as simulation time. A single layer Butler matrix network, the couplers occupies a significant amount of the printed circuit board area. The Butler matrix network consists of $N(n / 2)$ or $N / 2 \log _{2} N$ branch-line couplers. And, $(N / 2)(n-1)$ or $(N / 2) \log _{2}(N-1)$ phase shifters is needed. The number of the required crossovers, $C$ can be calculated as

$$
C_{n}=2 C_{n-1}+2^{n-2}\left(2^{n-2}-1\right)
$$

where $n$ is the matrix order, which is related to the number of ports by $N=2^{n}$ and $n$ should be equal to or greater than 2 . When the number of couplers involved in the implementation of Butler matrix network is higher, larger size will be needed. Dividing the whole BMN structure is very useful graphical technique to visualize the effect of component changes, especially the actual phase shift. The actual phase studies usually well-known as phase unwrapping [2] in the field of interferometry signal processing and magnetic resonance imaging.

\section{Butler matrix beam-forming network}

Fig. 1 shows the theoretical $4 x 4$ Butler matrix network which consists of four branch-line couplers, two crossovers and two phase shifter. The $4 x 4$ Butler matrix network has four inputs $1 \mathrm{R}, 2 \mathrm{~L}, 2 \mathrm{R}$ and $1 \mathrm{~L}$ as well as four outputs A1, A2, A3, and A4. The outputs are used as inputs to antenna elements to produce four beams. The input and output ports are named according to their signal introduced and beam position respectively. In order to illustrate the proposed method, a $2.3 \mathrm{GHz}$ microstrip BMN structure is designed. In developing the $4 \times 4$ BMN structure, several sub-structures are characterized in order to investigate the phase and magnitude of the BMN. Besides that, this enables simple and effective fine tuning of the physical dimension and errors cause by discontinuities [3, 4]. And, the models are very useful building library block for complicated BMN structure and others microwave circuits. Theoretically, the phase shift cause by the crossover is neglected as it is assumed to be zero. However, practically, the BMN should take account of phase shift as a result of the designed microstrip crossover coupler.

In developing the BMN structure, simpler sub-structure such as microstrip bend and T-junction are used as a substitute for the branch-line coupler and 


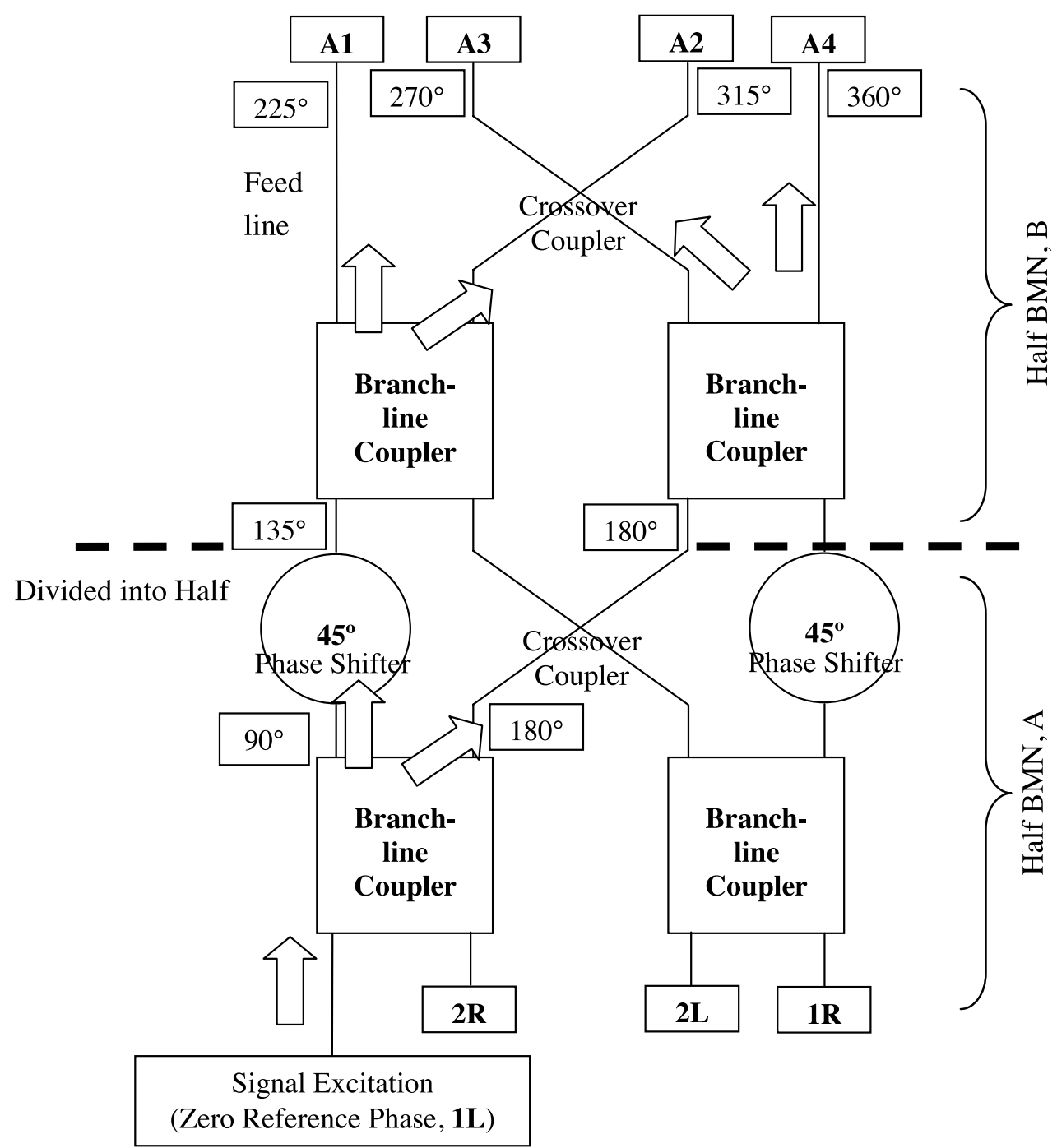

Fig. 1. Microstrip $4 \times 4$ Butler matrix beam-forming network theoretical actual phase progression without taking consideration of the crossover

crossover coupler. The branch-line coupler is model with four microstrip T-junction structures, while the crossover coupler is model with six equal width microstrip T-junction structures. Hence, smaller number of mesh [5] is required to investigate the couplers. In order to study and fine tune the required phase shifter and feed line, only half of the BMN needed to be modeled and designed.

\section{Model re-use and simulation time reduction}

In order to reduce the time needed to design and develop the microstrip branch-line coupler as shown in Fig. 2, the structure is divided into four parts. They are four unequal width microstrip T-junction structures. Since all the four structures are identical, only one microstrip T-junction is required to be investigated. Besides that, divergence of the simulation response can be observed clearly throughout the optimization and fine tuning. Similar to the branch-line coupler, the microstrip crossover coupler is divided into six 
parts for analysis. They are six equal width microstrip T-junction structures as shown in Fig. 2. The serial and shunt branch are fine tuned accordingly in order to obtain the required electrical length. The physical dimensions of the model are tuned in order to obtain a quarter of electrical wavelengths. The signal ports are relocated or de-embedding gradually in order to investigate the $\mathrm{S}_{21}$ and $\mathrm{S}_{31}$ phases. All the simulated models are recorded as the library files within the electromagnetic simulation tool. They are re-using for developing the upper and lower half of the BMN structure for time saving.

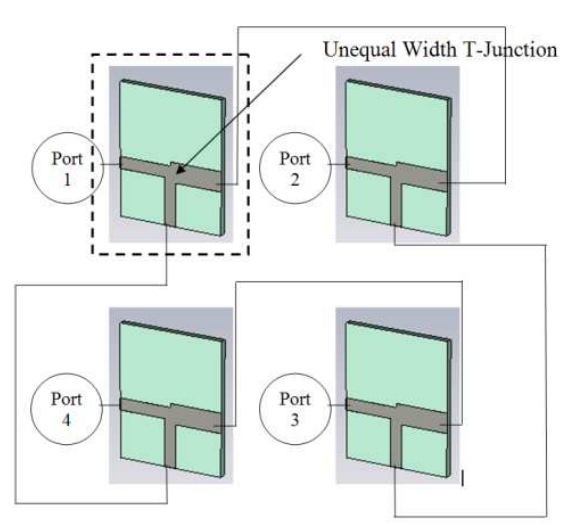

(a)

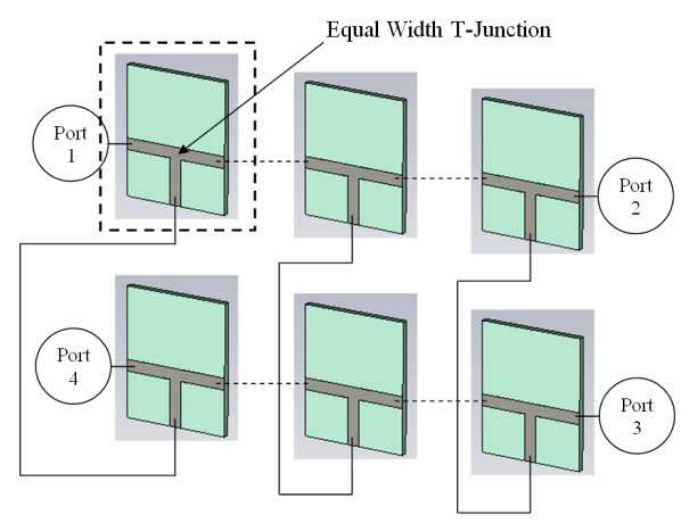

(b)
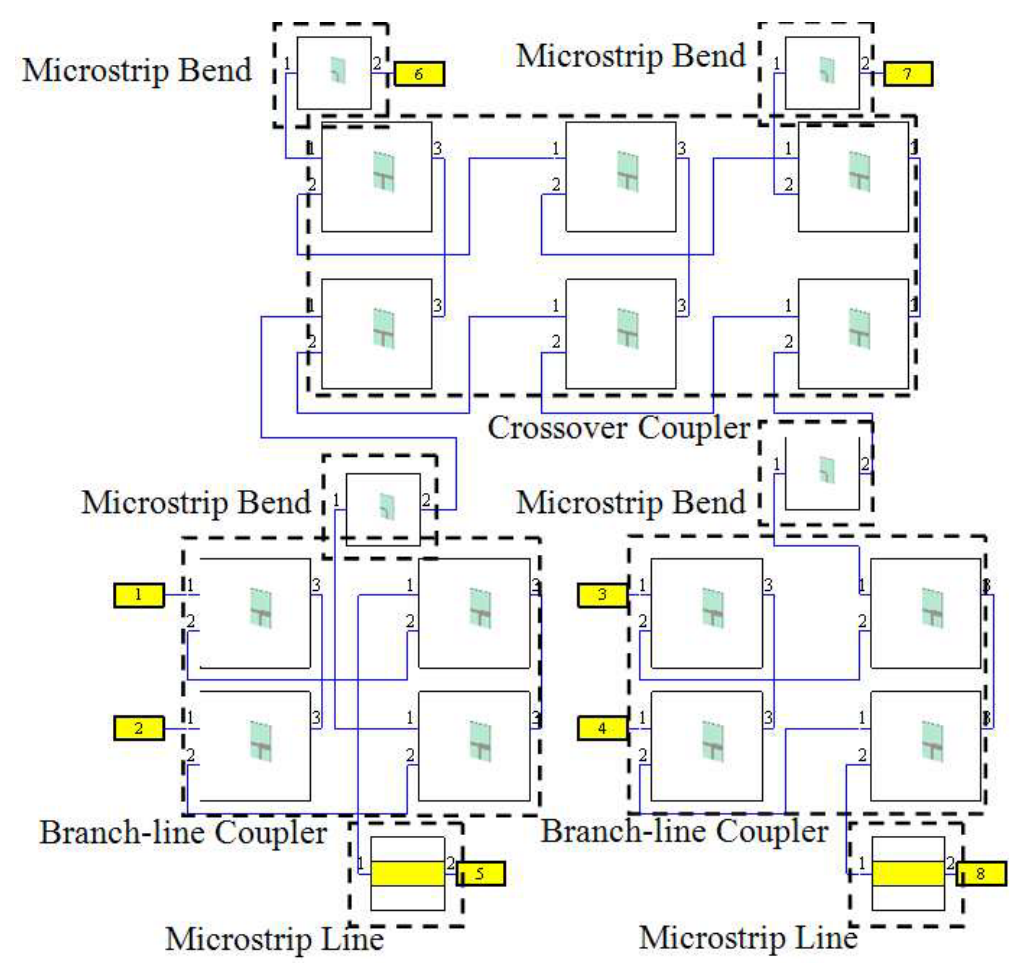

(c)

Fig. 2. Substructure of $4 \times 4$ Butler matrix beam-forming network (a) branch-line coupler (b) crossover coupler (c) upper or lower half of BMN structure 


\section{Tuning of BMN structure with single microstrip line}

With this proposed approach, the required electrical length of the phase shifter and feed line is determined easily without running the electromagnetic simulator [6]. It is because electromagnetic simulator is generally consuming a lot of simulation time. In determine the proper phase shift value for the phase shifter and feed line, only a single microstrip line is calculated or simulated with circuit simulator as shown in Fig. 2. Considering the size of the BMN structure, a lot of simulation time is needed in resolving the correct electrical length for the phase shifter and feed line if entire BMN structure is simulated. After the electrical length is determined, an appropriate phase shifter/feed line is designed and fit into the upper and lower half of the BMN structure. The restricted size or physical length of the phase shifter can be calculated. As for comparison, the entire microstrip upper and lower half of structure is simulated in order to obtain the S-parameter results. The simulation time is recorded with spreadsheet for comparison.

Table I. Total time consummated for each result simulation cycle

\begin{tabular}{|l|c|c|c|c|c|c|c|c|}
\hline & $\begin{array}{c}\text { Upper } \\
\text { Half } \\
\text { BMN } \\
\text { (One } \\
\text { Port) }\end{array}$ & $\begin{array}{c}\text { Upper } \\
\text { Half } \\
\text { BMN } \\
\text { (Four } \\
\text { Ports) }\end{array}$ & $\begin{array}{c}\text { Upper } \\
\text { Half } \\
\text { BMN } \\
\text { (Feed } \\
\text { Line) }\end{array}$ & $\begin{array}{c}\text { Upper } \\
\text { Half } \\
\text { BMN } \\
\text { (Circuit } \\
\text { Model) }\end{array}$ & $\begin{array}{c}\text { Lower } \\
\text { Half } \\
\text { BMN } \\
\text { (One } \\
\text { Port) }\end{array}$ & $\begin{array}{c}\text { Lower } \\
\text { Half } \\
\text { BMN } \\
\text { (Four } \\
\text { Ports) }\end{array}$ & $\begin{array}{c}\text { Lower } \\
\text { Half } \\
\text { BMN } \\
\text { (Phase } \\
\text { Shifter) }\end{array}$ & $\begin{array}{c}\text { Lower } \\
\text { Half } \\
\text { BMN } \\
\text { (Circuit } \\
\text { Model) }\end{array}$ \\
\hline $\begin{array}{l}\text { Number of } \\
\text { mesh cells }\end{array}$ & 1396120 & 1396120 & 716850 & N/A & 1396120 & 1404480 & 716850 & N/A \\
\hline $\begin{array}{l}\text { Number of } \\
\text { threads } \\
\text { used }\end{array}$ & 4 & 4 & 4 & N/A & 4 & 4 & 4 & N/A \\
\hline $\begin{array}{l}\text { Solver time } \\
\text { Total }\end{array}$ & $896 \mathrm{~s}$ & $808 \mathrm{~s}$ & 259 & N/A & $896 \mathrm{~s}$ & $845 \mathrm{~s}$ & 259 & N/A \\
\hline $\begin{array}{l}\text { simulation } \\
\text { time }\end{array}$ & $899 \mathrm{~s}$ & $6069 \mathrm{~s}$ & $580 \mathrm{~s}$ & $5 \mathrm{~s}$ & $899 \mathrm{~s}$ & $6237 \mathrm{~s}$ & $580 \mathrm{~s}$ & $4 \mathrm{~s}$ \\
\hline
\end{tabular}

By understanding the actual phase progression of the theoretical BMN structure as shown in Fig. 1, the desired phase value of the phase shifter and feed line is 45 degree and 90 degree respectively. Both of the values are determined by using the same developed sub-structure which includes Tjunctions, microstrip bends and microstrip lines. Subsequent of fine tuning the upper and lower BMN structure, the complete BMN structure as shown in Fig. 1 is simulated in order to obtain the frequency response. Hypothetically, as the port 1, 2, 3 and 4 initiated, the differences of the phases between consecutive outputs are given by

$$
\begin{gathered}
1 L=A 1 \angle 45^{\circ}+A 2 \angle 90^{\circ}+A 3 \angle 135^{\circ}+A 4 \angle 180^{\circ} \\
2 R=A 1 \angle 135^{\circ}+A 2 \angle 0^{\circ}+A 3 \angle 225^{\circ}+A 4 \angle 90^{\circ} \\
2 L=A 1 \angle 90^{\circ}+A 2 \angle 225^{\circ}+A 3 \angle 0^{\circ}+A 4 \angle 135^{\circ} \\
1 R=A 1 \angle 180^{\circ}+A 2 \angle 135^{\circ}+A 3 \angle 90^{\circ}+A 4 \angle 45^{\circ}
\end{gathered}
$$

In order to study the effect of the phase error on the array antennas far-field 
pattern, a simple patch antenna is modeled and simulated. The 4 element patch antenna array is then simulated with phase results obtained from the proposed BMN structure. The far-field radiation pattern of the array antennas are calculated accordingly in order to make comparison. The main lobe direction and beam-width are found to be very close to the ideal far-field pattern. Hence, the proposed approach in developing the BMN structure is fast, systematic and accurate.

\section{Conclusion}

The proposed approach is intended to reduce the simulation iterations by maintaining the amount of the crucial mesh cells. Although better mainframe and graphical processing unit can used to improve the simulation time, they come with production cost. The blueprint or architecture of the BMN structure is map accordingly in order to minimize the simulation time and task. The investigated sub-structures are mainly microstrip bend, microstrip T-junction and microstrip stepped width in order to gain the intuitive experience in fine tuning the BMN. The blueprint mapping is very useful graphical technique to visualize the effect of component changes. Besides that, the phase of the structures are unwrapped in order to study the actual phase progression. The modeled sub-structures is standardized and reused again without further design iteration. The entire BMN divided into two part for simulation time saving. From the recorded simulation time, a lot time is saved for developing the BMN structure.

\section{Acknowledgments}

The research work at Universiti Tenaga Nasional (Uniten) is financially supported by Ministry of Science, Technology and Innovation of Malaysia under eScience Fund. 